\title{
Degradabilidade in situ da matéria seca de forrageiras tropicais obtidas em diferentes épocas de corte
}

[In situ dry matter degradation of tropical forages harvested at different ages]

\author{
A.L.P. Rodrigues ${ }^{1}$, I.B.M. Sampaio ${ }^{1 *}$, J.C. Carneiro $^{2}$, T.R. Tomich $^{3}$, R.G.R. Martins ${ }^{4}$ \\ ${ }^{1}$ Escola de Veterinária - UFMG \\ Caixa Postal 567 \\ 30123-970 - Belo Horizonte, MG \\ ${ }^{2}$ EMBRAPA - Gado de Leite - Juiz de Fora, MG \\ ${ }^{3}$ EMBRAPA - Pantanal - Corumbá, MS \\ ${ }^{4}$ Departamento de Zootecnia - UFV - Viçosa, MG
}

\begin{abstract}
RESUMO
Estimou-se a degradabilidade in situ de 10 forrageiras tropicais em três idades ao corte (21, 42 e 63 dias) e em três tempos de incubação (6, 24 e 96h). As forrageiras utilizadas foram: Andropogon gayanus cv. Planaltina, Brachiaria brizantha (acessos 3401, 3413 e 3451 CPAC), Cenchrus ciliaris (acessos 79119, 79146, 79148, 80199 e 81302 CPATSA) e Panicum maximum (3616 CPAC). Os acessos de B. brizantha, $P$. maximum e A. gayanus apresentaram os maiores valores de degradabilidade da matéria seca e os de $C$. ciliaris os valores mais baixos. Todas as forrageiras apresentaram queda no desaparecimento da matéria seca com o avanço da idade. Os acessos de Brachiaria brizantha 3413 e 3451 apresentaram as maiores degradabilidades efetivas.
\end{abstract}

Palavras-chave: bovino, degradabilidade in situ, forrageira

\begin{abstract}
The ruminal degradability of 10 tropical forages at three cutting times $(21,42$ and 63 days) incubated at 6, 24 and 96 hours using the in situ technique was estimated. The forages were: Andropogon gayanus $c v$. Planaltina, Brachiaria brizantha (accesses 3401, 3413, 3451 CPAC), Cenchrus ciliaris (accesses 79119, 79146, 79148, 80199 and 81302 CPATSA) and Panicum maximum (3616 CPAC). The accesses of B. brizantha, P. maximum and A. gayanus $c v$ Planaltina presented the highest dry matter degradability values and the accesses of $\mathrm{C}$. ciliaris the lowest. For all forages, increased cutting age led to dry matter reduction. The accesses of $\mathrm{B}$. brizantha 3413 and 3451 presented the best effective degradabilities.
\end{abstract}

Keywords: bovine, in situ degradability, forages

\section{INTRODUÇÃO}

A maioria das forrageiras tropicais apresenta alta porcentagem de parede celular e baixo conteúdo celular. O conteúdo celular, representado pela fração solúvel, mostra, potencialmente, $100 \%$ de digestibilidade. A parede celular, constituída pela fração insolúvel, apresenta potencial de degradação mais baixo, sendo resistente ao ataque de enzimas do trato gastrintestinal de ruminantes. Entretanto, devido à presença de microrganismos, os carboidratos estruturais

Recebido para publicação em 5 de setembro de 2003

Recebido para publicação, após modificações, em 13 de abril de 2004

* Autor para correspondência

E-mail: ivan@vet.ufmg.br 
presentes na parede celular podem ser degradados no rúmen.

A susceptibilidade à degradação ruminal da porção fibrosa varia entre espécies e com a idade ou nível de maturação da forrageira. À medida em que se avança no desenvolvimento vegetal rumo ao estágio de maturação, ocorre drástica diminuição do teor protéico e aumento do teor de fibra, associado ao aumento no teor de lignina. A lignina forma uma barreira que impede a aderência microbiana e a hidrólise enzimática da celulose e hemicelulose, indisponibilizando os carboidratos estruturais potencialmente degradáveis, diminuindo a digestibilidade da fibra e a qualidade e o aproveitamento da forragem.

Várias técnicas (in vivo, in vitro, in situ) têm tentado quantificar as frações solúvel e fibrosa das forrageiras. A técnica in situ tem sido a mais recomendada pela rapidez na obtenção dos dados, simplicidade e economia. Ela requer pequena quantidade de amostras de alimento, além de possibilitar sua exposição ao ambiente ruminal. Apesar de ter sido inicialmente usada para avaliação da degradabilidade de proteína, tem sido recomendada para avaliar forragens $\mathrm{e}$ fibra (Orskov, 1980; Huntington e Givens, 1995).

Tendo em vista a grande variação edafoclimática das regiões produtivas do Brasil, a variabilidade genética das espécies forrageiras disponíveis e a busca por materiais cada vez mais adaptados, produtivos e de boa qualidade, é de suma importância o estudo do desempenho de forrageiras em nutrição animal.

A avaliação da degradação ruminal de forrageiras em diferentes idades ao corte permite não só a comparação entre diferentes espécies mas também o estudo do melhor estágio de maturação para sua utilização. Sabe-se, ainda, que a produção de matéria seca deve influenciar a escolha e o manejo de forrageiras.

Este trabalho teve como objetivo comparar, em bovinos, o percentual de degradação ruminal das gramíneas forrageiras Andropogon gayanus cv Planaltina, Brachiaria brizantha (acessos 3401,3413, 3451 CPAC), Cenchrus ciliaris (acessos 79119, 79146, 79148, 81302, 81306 CPATSA) e Panicum maximum (acesso 3616 CPAC), em três idades de corte.

\section{MATERIAL E MÉTODOS}

Foram utilizados três novilhos mestiços, entre 18 e 24 meses de idade, peso vivo médio de $350 \mathrm{~kg}$, portadores de cânula ruminal de PVC com diâmetro de $5 \mathrm{~cm}$.

As gramíneas foram semeadas e colhidas no centro de Pesquisa Agronômica de Minas Gerais da Epamig, na cidade de Janaúba. Foram utilizadas 10 forrageiras em três idades de corte (2, 42 e 63 dias). As forrageiras foram: Cenchrus ciliaris (acessos 81302, 79146, 79119, 79148, 81306 CPATSA), Brachiaria brizantha (acessos 3413, 3401, 3451 CPAC), Andropogon gayanus cv Planaltina e Panicum maximum (acesso 3616 CPAC). Após serem colhidas, as forrageiras foram secas ao sol e colocadas em estufa ventilada a $65^{\circ} \mathrm{C}$ durante 48 horas. Em seguida foram moídas com peneiras de $4 \mathrm{~mm}$ em moinho tipo Willey modelo 4 e acondicionadas em sacos plásticos hermeticamente fechados.

A degradabilidade da matéria seca (DMS) foi estimada pela técnica in situ utilizando sacos de náilon medindo $12 \times 8 \mathrm{~cm}$ e com poros de 40 a $60 \mu \mathrm{m}$, contendo aproximadamente $5 \mathrm{~g}$ do material preparado, para posterior incubação no rúmen (Nocek, 1988). Os tempos de incubação utilizados foram 6, 24 e 96 horas (Sampaio et al., 1995).

O delineamento experimental foi em parcelas subdivididas, em esquema fatorial $3 \times 10 \times 3$ (três tempos de incubação nas parcelas e 10 forrageiras em três idades de corte nas subparcelas). Para cada tempo de incubação 10 sacos foram sorteados para um mesmo rúmem. A percentagem de DMS em cada tempo foi calculada pela proporção de alimento que desapareceu nos sacos após a incubação no rúmen. O modelo de DMS foi estimado segundo Orskov e McDonald (1979), na versão modificada por Sampaio (1988), e a degradabilidade efetiva da matéria seca (DEMS) foi estimada segundo Orskov e McDonald (1979), levando-se em conta a taxa de passagem de sólidos no rúmen de 2 e $5 \% / \mathrm{h}$ (Nutrient..., 1984).

Do material original obtiveram-se amostras moídas a $1 \mathrm{~mm}$ e analisadas para: MS e proteína bruta (PB) utilizando-se o método Kjeldahl (Official..., 1995); fibra em detergente neutro 
(FDN), fibra em detergente ácido (FDA) e lignina usando-se o método seqüencial de Robertson e Van Soest (1981).

\section{RESULTADOS E DISCUSSÃO}

Os teores de proteína diminuiram com o avanço da idade, de $12,3 \%$ a 3,1\% (Tab. 1). Algumas gramíneas experimentaram quedas mais acentuadas que outras. O Andropogon gayanus e os acessos de Brachiaria brizantha e Panicum maximum apresentaram teores de proteína iguais ou superiores ao nível mínimo de proteína exigido pelos microrganismos no rúmen $(7 \%$ segundo Van Soest, 1994), em todas as épocas de corte. Os acessos de Cenchrus ciliaris, à exceção do 79146, apresentaram esse teor apenas aos 21dias de idade. Os valores de FDN $(65,9 \pm 4,0 \%), \quad$ FDA $(36,4 \pm 5,1 \%)$ e celulose (CEL) $(31,7 \pm 3,9 \%)$ não oscilaram muito segundo idade ou mesmo entre as forrageiras, sendo os mais altos observados na C. ciliaris e os mais baixos na $P$. maximum. Os valores de hemicelulose (HEM) $(29,5 \pm 2,7 \%)$ apresentaram pouca variação segundo a idade ou a forrageira. Os valores de lignina (LIG) $(4,36 \pm 1,45)$, como era esperado, aumentaram com a idade de corte, mais intensamente nos acessos de $C$. ciliairis e $A$. gayanus.

Tabela 1. Composição das forrageiras (\% sobre a matéria seca), segundo a idade de corte em dias

\begin{tabular}{|c|c|c|c|c|c|c|c|}
\hline Forrageira & Idade & PB & FDN & FDA & CEL & HEM & LIG \\
\hline \multirow{3}{*}{ A. gayanus } & 21 & 11,86 & 64,40 & 32,50 & 30,11 & 31,83 & 2,32 \\
\hline & 42 & 7,88 & 66,28 & 34,61 & 30,95 & 31,67 & 3,19 \\
\hline & 63 & 6,92 & 64,68 & 32,71 & 26,58 & 31,96 & 5,84 \\
\hline \multirow{3}{*}{ B. brizanta $(3401)$} & 21 & 9,03 & 66,56 & 32,90 & 30,26 & 33,65 & 2,89 \\
\hline & 42 & 9,05 & 61,84 & 31,95 & 28,14 & 29,89 & 3,32 \\
\hline & 63 & 7,35 & 62,71 & 32,10 & 28,53 & 30,61 & 3,39 \\
\hline \multirow{3}{*}{ B. brizanta (3413) } & 21 & 9,60 & 64,14 & 32,20 & 29,55 & 31,93 & 2,68 \\
\hline & 42 & 11,11 & 60,50 & 29,24 & 25,86 & 31,25 & 3,09 \\
\hline & 63 & 7,04 & 60,96 & 31,10 & 28,49 & 29,86 & 2,96 \\
\hline \multirow{3}{*}{ B. brizanta $(3451)$} & 21 & 12,31 & 59,03 & 27,49 & 25,09 & 31,53 & 3,68 \\
\hline & 42 & 8,78 & 61,92 & 31,67 & 27,39 & 30,25 & 4,11 \\
\hline & 63 & 7,51 & 63,58 & 34,67 & 29,88 & 28,90 & 4,59 \\
\hline \multirow{3}{*}{ C. ciliaris (79119) } & 21 & 8,53 & 66,27 & 38,77 & 34,74 & 27,49 & 3,87 \\
\hline & 42 & 4,81 & 70,72 & 43,03 & 36,87 & 27,69 & 5,52 \\
\hline & 63 & 4,29 & 71,87 & 44,12 & 38,21 & 27,76 & 5,87 \\
\hline \multirow{3}{*}{ C. ciliaris (79146) } & 21 & 9,85 & 63,04 & 33,23 & 29,27 & 29,81 & 3,46 \\
\hline & 42 & 7,96 & 67,74 & 37,47 & 32,11 & 30,27 & 3,43 \\
\hline & 634 & 5,46 & 68,83 & 38,58 & 33,38 & 30,25 & 4,54 \\
\hline \multirow{3}{*}{ C. ciliaris(79148) } & 21 & 9,61 & 65,14 & 38,66 & 34,48 & 26,47 & 3,94 \\
\hline & 42 & 6,43 & 70,79 & 41,47 & 35,64 & 29,31 & 5,64 \\
\hline & 63 & 3,61 & 71,63 & 42,87 & 35,26 & 28,75 & 7,37 \\
\hline \multirow{3}{*}{ C. ciliaris (80199) } & 21 & 8,11 & 63,06 & 38,77 & 34,81 & 24,29 & 3,54 \\
\hline & 42 & 4,13 & 70,47 & 43,32 & 32,08 & 36,50 & 5,22 \\
\hline & 63 & 3,11 & 69,38 & 43,70 & 34,49 & 25,67 & 8,64 \\
\hline \multirow{3}{*}{ C. ciliaris (81302) } & 21 & 7,09 & 66,95 & 42,59 & 35,61 & 24,36 & 5,26 \\
\hline & 42 & 4,54 & 70,60 & 43,03 & 37,47 & 27,57 & 4,81 \\
\hline & 63 & 3,34 & 72,38 & 46,63 & 39,59 & 25,75 & 6,31 \\
\hline \multirow{3}{*}{ P. maximum (3616) } & 21 & 12,10 & 61,36 & 33,36 & 29,04 & 27,99 & 3,80 \\
\hline & 42 & 9,76 & 63,99 & 32,53 & 27,52 & 31,46 & 3,79 \\
\hline & 63 & 6,87 & 63,61 & 33,32 & 29,21 & 30,29 & 3,62 \\
\hline
\end{tabular}


A degradabilidade das forrageiras já estava diferenciada aos 42 dias de idade (Tab. 2). Os acessos de $B$. brizanta e $P$. maximum foram os que apresentaram os maiores desaparecimentos da matéria seca, e A. gayanus e os acessos de $C$. ciliaris, os menores. Isto provavelmente pode ser explicado pelas diferenças encontradas na composição bromatológica do material, isto é, as forrageiras com menores teores de FDN e lignina apresentaram os maiores desaparecimentos, e as com maiores teores de FDN, FDA e lignina, os menores desaparecimentos da matéria seca. Estes resultados estão de acordo com os de Moore e Miller (1988) e Gaillard (1962), que sugeriram ser a diferença na composição da parede celular a explicação da menor digestibilidade do caule em relação à das folhas. A proporção de carboidratos da parede celular e seu conteúdo de lignina são os fatores que mais afetam a redução da qualidade das gramíneas tropicais. Van Soest (1994) afirmou que o teor de FDN das forragens é negativamente correlacionado com o seu consumo. Forragens com menor fração fibrosa refletem maior digestibilidade e maior consumo.

Tabela 2. Valores médios de desaparecimento da matéria seca (\%) segundo a forrageira, o tempo de incubação e a idade da planta

\begin{tabular}{|c|c|c|c|c|c|c|c|c|c|}
\hline \multirow{4}{*}{ Forrageira } & \multicolumn{9}{|c|}{ Tempo de incubação } \\
\hline & \multicolumn{3}{|c|}{6 horas } & \multicolumn{3}{|c|}{24 horas } & \multicolumn{3}{|c|}{96 horas } \\
\hline & \multicolumn{3}{|c|}{ Idade em dias } & \multicolumn{3}{|c|}{ Idade em dias } & \multicolumn{3}{|c|}{ Idade em dias } \\
\hline & 21 & 42 & 63 & 21 & 42 & 63 & 21 & 42 & 63 \\
\hline A. gayanus & $19,2 \mathrm{aA}$ & $19,0 \mathrm{bcdA}$ & $17,9 \mathrm{bcA}$ & $41,9 \mathrm{abcA}$ & $32,6 \mathrm{cdefB}$ & $34,2 \mathrm{cB}$ & $77,3 \mathrm{abA}$ & $73,6 \mathrm{aAB}$ & $70,2 \mathrm{abB}$ \\
\hline B.brizanta (3451) & $24,8 \mathrm{aA}$ & $22,7 \mathrm{abcA}$ & $21,0 \mathrm{abcA}$ & $49,0 \mathrm{bA}$ & $39,9 \mathrm{abcdA}$ & $46,2 \mathrm{aB}$ & $76,9 \mathrm{abcA}$ & $74,8 \mathrm{aA}$ & $65,3 \mathrm{abB}$ \\
\hline B. brizanta (3413) & $25,5 \mathrm{aA}$ & $28,5 \mathrm{aA}$ & $27,6 \mathrm{aA}$ & $45,8 \mathrm{abA}$ & $47,4 \mathrm{aA}$ & $46,1 \mathrm{aA}$ & $73,9 \mathrm{bcdA}$ & $77,2 \mathrm{aAB}$ & $71,2 \mathrm{abB}$ \\
\hline B. brizanta (3401) & $23,8 \mathrm{aA}$ & $24,00 \mathrm{abcA}$ & $22,7 \mathrm{abA}$ & $43,2 \mathrm{abcA}$ & $40,7 \mathrm{abcA}$ & $44,4 \mathrm{aA}$ & $81,4 \mathrm{aA}$ & $76,9 \mathrm{aAB}$ & $72,0 \mathrm{aB}$ \\
\hline C.ciliaris (79119) & $19,4 \mathrm{aA}$ & $14,3 \mathrm{dA}$ & $14,1 \mathrm{cA}$ & $36,9 \mathrm{cA}$ & $26,1 \mathrm{fB}$ & $30,3 \mathrm{cB}$ & $67,8 \mathrm{deA}$ & $54,9 \mathrm{bB}$ & $49,0 \mathrm{deB}$ \\
\hline C.ciliaris (79146) & $20,5 \mathrm{aA}$ & $20,1 \mathrm{bcdA}$ & $16,5 \mathrm{bcA}$ & $39,9 \mathrm{bcA}$ & $35,7 \mathrm{bcdeA}$ & $35,5 \mathrm{bcA}$ & $69,2 \mathrm{cdeA}$ & $60,3 \mathrm{bB}$ & $56,4 \mathrm{cdB}$ \\
\hline C.ciliaris (79148) & $20,8 \mathrm{aA}$ & $15,5 \mathrm{bcdA}$ & $17,6 \mathrm{bcA}$ & $37,1 \mathrm{cA}$ & 32,5 defAB & $28,9 \mathrm{cB}$ & $65,0 \mathrm{cA}$ & $58,6 \mathrm{bB}$ & $47,0 \mathrm{eC}$ \\
\hline C.ciliaris (80199) & $21,4 \mathrm{aA}$ & $16,6 \mathrm{cdAB}$ & $15,4 \mathrm{bcB}$ & $39,9 \mathrm{bcA}$ & $30,3 \mathrm{efB}$ & $30,5 \mathrm{cB}$ & $71,1 \mathrm{bcdeA}$ & $60,5 \mathrm{bB}$ & $50,1 \mathrm{deC}$ \\
\hline C.ciliaris (81302) & $19,1 \mathrm{aA}$ & $14,6 \mathrm{dA}$ & $14,5 \mathrm{cA}$ & $39,0 \mathrm{bcA}$ & $42,7 \mathrm{abA}$ & $30,1 \mathrm{cB}$ & $67,1 \mathrm{deA}$ & $55,3 \mathrm{bB}$ & $49,0 \mathrm{deC}$ \\
\hline P.maximum (3616) & $22,5 \mathrm{aA}$ & $24,8 \mathrm{abA}$ & $23,3 \mathrm{abA}$ & 42,1abcA & 38,3 bcdeA & $42,3 \mathrm{abA}$ & $69,2 \mathrm{bcdeA}$ & $70,3 \mathrm{aA}$ & $62,1 \mathrm{bcB}$ \\
\hline
\end{tabular}

Nas colunas, médias com pelo menos uma letra minúscula comum são equivalentes.

Nas linhas, para um mesmo tempo de incubação, letras maiúsculas distintas indicam diferentes percentagens de desaparecimento entre idades de corte $(\mathrm{P}<0,05)$.

O efeito da época do corte (idade da planta) passa a ser percebido a partir de 24 horas de incubação, quando os acessos de $B$. brizantha mostraram-se menos sensíveis a esse efeito. Com 96 horas de incubação, o primeiro e o segundo cortes (21 e 42 dias) apresentaram resultados semelhantes para DMS, exceto para os acessos de $C$. ciliaris, mais sensíveis ao efeito de idade ao corte. O corte aos 63 dias de idade resultou em decréscimo significativo na DMS para todas as forrageiras. Na Tab. 3 estão registrados os parâmetros das equações de degradação em função do tempo de incubação para cada forrageira e idade de corte, DMS=A-B.exp(ct). Segundo Sampaio (1988), valores de A maiores que 100 ou de c menores que 0,01 indicam inadequacidade do modelo aos pontos observados ou respostas atípicas (erro experimental), resultando em estimativas de digestibilidade efetiva que devem ser vistas com a devida restrição. Este foi o caso para o $A$. gayanus e C. ciliaris com 42 dias de idade. De modo geral, o último corte resultou em menor degradabilidade potencial (A) da matéria seca para todas as forrageiras. Os acessos de $B$. brizantha, $A$. gayanus e $P$. maximum apresentaram maiores valores de degradabilidade potencial. Villareal (1994), ao trabalhar com acessos de Brachiaria, Panicum e Andropogon, encontrou menor digestibilidade para os acessos de Braquiaria. A taxa de degradação c variou entre os acessos. Vários apresentaram taxas desejáveis $(c>0,025)$, o que beneficiou seus valores de digestibilidade efetiva (DE). Com o 
aumento da idade da planta, o valor da DE diminuiu, mais perceptível para os acessos de $C$. ciliaris. Os melhores valores de DE foram observados para os acessos de $B$. brizantha e $P$. maximum, nas diversas idades de corte. Elas também foram as forrageiras que apresentaram menores teores de FDN e lignina e maiores valores de degradabilidade potencial e taxa de degradação.

Tabela 3. Degradabilidade potencial (A), fração degradável no rúmen (B, se não houvesse tempo de colonização), taxa de degradação (c), coeficiente de determinação $\left(\mathrm{R}^{2}\right)$, fração solúvel no empo zero $(\mathrm{S})$ e digestibilidade efetiva (DE2\% e DE5\%, para taxas de passagem de 2 e 5\%), relativos aos modelos de degradação da matéria seca, segundo as forrageiras e suas idades de corte

\begin{tabular}{|c|c|c|c|c|c|c|c|c|}
\hline Forrageira & Idade & $\bar{A}$ & B & c. $10^{2}$ & $\mathrm{R}^{2}$ & $\mathrm{~S} \%$ & DE $2 \%$ & DE 5\% \\
\hline \multirow{3}{*}{ A. planaltina } & 21 & 85,3 & 76,1 & 2,3 & 93,7 & 10,9 & 52,7 & 34,9 \\
\hline & 42 & 142,9 & 128,8 & 6,4 & 91,3 & 10,3 & 41,7 & 24,8 \\
\hline & 63 & 94,1 & 82,7 & 1,3 & 94,3 & 6,1 & 38,9 & 27,5 \\
\hline \multirow{3}{*}{ B. brizanta $(3401 \mathrm{AC})$} & 21 & 97,3 & 81,3 & 1,7 & 93,3 & 17,4 & 54,7 & 38,0 \\
\hline & 42 & 94,4 & 77,3 & 1,5 & 91,2 & 18,0 & 47,5 & 31,0 \\
\hline & 63 & 73,9 & 61,6 & 3,1 & 99,1 & 17,7 & 55,3 & 41,0 \\
\hline \multirow{3}{*}{ B. brizanta (3413) } & 21 & 78,8 & 62,5 & 2,6 & 98,9 & 18,9 & 54,5 & 40,6 \\
\hline & 42 & 84,4 & 64,3 & 2,4 & 93,3 & 21,5 & 47,7 & 34,1 \\
\hline & 63 & 75,4 & 56,3 & 2,7 & 99,4 & 17,2 & 49,5 & 36,9 \\
\hline \multirow{3}{*}{ B. brizanta $(3451)$} & 21 & 80,0 & 66,96 & 3,2 & 98,1 & 19,8 & 61,0 & 45,9 \\
\hline & 42 & 89,8 & 74,3 & 1,7 & 98,1 & 19,0 & 43,0 & 31,3 \\
\hline & 63 & 66,1 & 59,2 & 4,6 & 96,4 & 14,5 & 55,7 & 42,8 \\
\hline \multirow{3}{*}{ C. ciliaris (79119) } & 21 & 77,5 & 65,5 & 2,0 & 96,5 & 14,5 & 47,2 & 33,2 \\
\hline & 42 & 75,7 & 66,1 & 1,2 & 97,0 & 10,0 & 27,9 & 19,5 \\
\hline & 63 & 51,0 & 44,8 & 3,2 & 97,2 & 7,8 & 35,5 & 25,4 \\
\hline \multirow{3}{*}{ C. ciliaris (79146) } & 21 & 75,4 & 63,4 & 2,4 & 96,1 & 16,3 & 50,9 & 36,9 \\
\hline & 42 & 65,6 & 52,5 & 2,4 & 98.0 & 13,3 & 37,3 & 25,2 \\
\hline & 63 & 58,5 & 51,3 & 3,3 & 97,1 & 9,3 & 41,4 & 29,9 \\
\hline \multirow{3}{*}{ C. ciliaris (79148) } & 21 & 73,0 & 59,1 & 2,1 & 95,6 & 14,3 & 44,4 & 31,6 \\
\hline & 42 & 65,6 & 54,6 & 2,1 & 98,0 & 12,7 & 35,9 & 22,9 \\
\hline & 63 & 51,4 & 38,7 & 2,3 & 97,6 & 6,4 & 27,0 & 18,5 \\
\hline \multirow{3}{*}{ C. ciliaris (80199) } & 21 & 79,7 & 66,2 & 2,1 & 96,7 & 16,3 & 50,4 & 36,0 \\
\hline & 42 & 78,8 & 67,6 & 1,4 & 95,5 & 12,5 & 40,1 & 27,2 \\
\hline & 63 & 54,3 & 45,9 & 2,7 & 95,4 & 11,7 & 38,2 & 27,9 \\
\hline \multirow{3}{*}{ C. ciliaris (81302) } & 21 & 72,2 & 62,1 & 2,6 & 96,3 & 13,1 & 48,1 & 34,3 \\
\hline & 42 & 55,4 & 60,9 & 0,7 & 67,5 & 10,6 & 43,6 & 31,8 \\
\hline & 63 & 51,3 & 44,3 & 3,1 & 94,6 & 9,7 & 36,5 & 26,5 \\
\hline \multirow{3}{*}{ P. maximum (3616) } & 21 & 73,8 & 60,3 & 2,7 & 96,8 & 17,3 & 51,8 & 38,3 \\
\hline & 42 & 94,2 & 74,7 & 1,2 & 96,3 & 16,2 & 44,3 & 30,7 \\
\hline & 63 & 65,2 & 51,3 & 3,4 & 95,7 & 15,7 & 47,9 & 36,3 \\
\hline
\end{tabular}

Estes resultados assemelham-se aos de Rolim (1976) e Lavezo et al. (1980) que, ao trabalharem com forrageiras tropicais cortadas em diferentes idades, observaram decréscimo na digestibilidade in vitro da matérica seca com o envelhecimento das plantas. Seiffert (1980), ao estudar variedades de Brachiaria, encontrou valores acima de $7,0 \%$ de proteína bruta e $50 \%$ de digestibilidade, quando cortadas aos 60dias de idade. Moore e Miller (1988) observaram grande variação na composição da fibra de $B$. bizantha, o que implicou em distintos valores para DE. Devasena et al. (1994) encontraram para o capim-colonião valores de $\mathrm{DE}$ iguais a 53,4, 38,1 e $39,0 \%$ aos 15,30 e 60 dias de idade, respectivamente. 
Singh et al. (1997) registraram valores de DMS para acessos de C. ciliaris iguais a $58,1,52,2$ e $39,8 \%$ nas idades de 30,60 e 90 dias, respectivamente, inferiores aos aqui obtidos.

Villareal (1994), ao estudar 17 gramíneas, encontrou em acessos de $P$. maximum alta digestibilidade in vitro, a qual diminuiu com a idade a partir de nove semanas. A degradação obsevada a partir da sexta semana foi semelhante ao das braquiárias. Esses resultados não estão de acordo com os obtidos neste experimento, no qual o acesso de $P$. maximum apresentou valores de DMS iguais àqueles das braquiárias na maioria dos tempos de incubação e idades de corte.

\section{CONCLUSÕES}

Todos os acessos de Brachiaria brizantha e o acesso de Panicum maximum (3616) apresentaram teor de PB igual ou superior a 7\% em todas as idades, teor médio de FDN igual a $62 \%$ e maior digestibilidade efetiva. São indicados para todas as épocas de corte testadas, de 21 a 63 dias de idade. Entre os acessos de Cenchrus, o 79146 apresentou teor de PB médio superior a $7 \%$ até os 42 dias de idade e teor de FDN menor que os demais acessos nas idades de corte testadas, o que sugere maior potencial forrageiro. O Andropogon gayanus e o acesso $C$. ciliaris (79148) foram as forrageiras com a menor digestibilidade efetiva.

\section{REFERÊNCIAS BIBLIOGRÁFICAS}

DEVASENA, B.; KRISHNA, N.; RAMA, P.J. et al. Effect of stage of growth on chemical composition and in sacco dry matter degradability of colonial grass. Indian J. Anim. Sci., v.64, p.1108-1110, 1994.

GAILLARD, B.D.E. The relationship between cell wall constituents of roughages and the digestibility of the organic matter. J. Agric. Sci., v.59, p.369-373, 1962.

HUNTINGTON, J.A.; GIVENS, D.I. The in situ technique for studying rumen degradation of feeds: a review of the procedure. Nutr. Abst. Rev. (Series B), v.65, p.63-95, 1995.
LAVEZO, W.; SILVEIRA, A.C.; GONÇALVES, D.A. et al. Efeito da idade da planta ao primeiro corte sobre a produção, composição bromatológica e alguns aspectos morfológicos de Brachiaria decumbens (S.). Rev. Soc. Bras. Zootec., v.9, p.656-672,1980.

MOORE, K.J.; MILLER, D.A. Cell wall composition and digestibility in five species of Brachiaria. Trop. Agric., v.65, p.337-340,1988.

NOCEK, J.E. In situ and other methods to estimate ruminal protein and energy digestibility. A review. J. Dairy Sci., v.71, p.2051-206, 1988.

NUTRIENT requirements of ruminant livestock. Farham Royal, UK: ARC, 1984.

OFFICIAL methods of analysis. Washington: AOAC, 1995.

ORSKOV, E.R.; HOVELL, F.D. de B. The use of nylon bag technique for the evaluation of feedstuffs. Trop. Anim. Prod., v.5, p.195-223. 1980.

ORSKOV, E.R.; McDONALD, I. The estimation of protein degradability in the rumen from incubation measurements weighted according to rate of passage. J. Agric. Sci., v.92, p.499-503, 1979.

ROBERTSON J.B.; VAN SOEST P.J. The detergent system of analysis and its application to human foods. In: JAMES, W.P.T.; THEANDER O. (Eds.). The analysis of dietary fiber in food. New York: Marcel Dekker,1981. P.123-158.

ROLIM, F.A. Efeito da maturidade sobre a produção e o valor nutritivo dos capins decumbens (Brachiaria decumbens), Estrela (Cynodon plectostaghus, K. Shum, Pilger) e Rhodes (Clorys gayana, k. cv. Callide). 1976. 59f. Dissertação (Mestrado em Zootecnia). Escola Superior de Agricultura Luiz de Queiroz, USP, Piracicaba, SP.

SAMPAIO, I.B.M. Experimental designs and modelling techiniques in the study of roughage degradation in the rumen and growth of ruminants. 1988. 114f. Thesis (PhD) University of Reading, Reading, UK.

SAMPAIO, I.B.M; PIKE, D.J.; OWEN, E. Optimal design for studying dry matter degradation in the rumen. Arq. Bras. Med. Vet. Zootec., v.47, p.373-383, 1985. 


\section{Rodrigues et al.}

SEIFFERT, N.F. Gramineas forrageiras do gênero Brachiaria. Circular Técnica. Centro Nacional de Pesquisa em Gado de Corte, EMBRAPA, 1980. 83p.

SINGH, K.K.; BANDLA, S.; RAMACHANDRA, K.S. Chemical changes with maturity and its impact on in sacco dry matter degradation of some range grasses and legumes. Indian J. Anim.
Nutr., v.14, p. 254-257, 1997.

VAN SOEST, P.J. Nutritional ecology of the ruminant. Cornell University, 1994. 476p.

VILLARREAL, M. Valor nutritivo de gramíneas y leguminosas forrajeras en San Carlos. Past. Trop., v.16, p.27-31, 1994. 